\title{
SUR LE MÉCANISME D'ÉCLOSION DES NYMPHES DE CULICIDÉS
}

\author{
Par Henri GALlIARD
}

Lorsque l'on examine une nymphe de Culicidé avant son éclosion (fig. I), on voit à son pôle antérieur, au point où se trouve la tête fortement fléchie de l'imago et où prennent naissance les antennes, deux

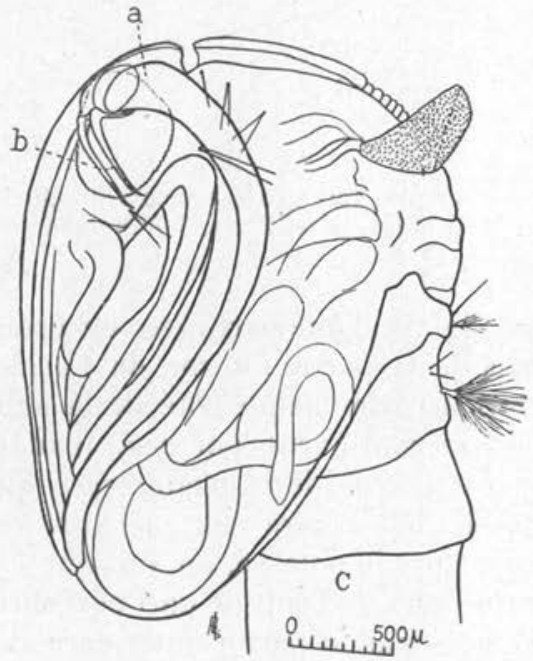

Fra. 1. - Nymphe de Culicidé éclaircie par la potasse; $a$, pla. que verticale; $b$, tiges chitineuses.

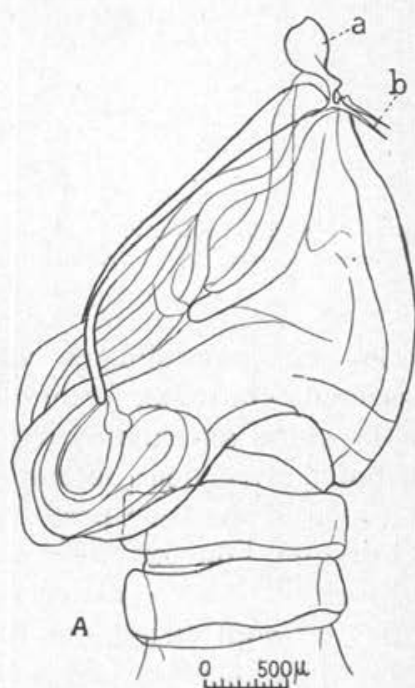

Fig. 2. - Mue d'une nymphe de Gulicidé. $a$, plaque verticale; $b$, tiges chitineuses.

plaques de l'enveloppe externe qui s'articulent. En avant, la plaque clypéale qui se continue en avant et en bas avec l'enveloppe superficielle de la gaine du labium, en arrière la plaque verticale en forme ansales de Parasitologir, T. XVIII, Nos 4-5-6. - 194r, p. 247-250. 
de pelle, suivant la comparaison de Crawford (I), et qui présente des caractères spécifiques suivant les diverses espèces.

C'est au point d'articulation de ces deux plaques que se trouve l'appareil d'éclosion. Lorsqu'on regarde l'enveloppe nymphale après la sortie de l'imago (fig* 2), on constate que la plaque dorsale est fendue longitudinalement mais que, en avant, la plaque verticale $(a)$ qui est médiane s'est soulevée et a basculé en avant, et que deux tiges fortement chitineuses $(b)$, insérées à la base de la plaque verticale font saillie hors de la cavité.

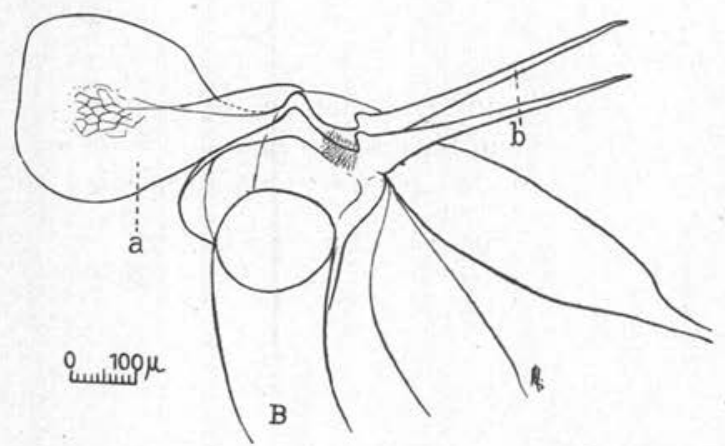

Fıg. 3. - Partie supérieure de la figure 2 à un plus fort grossissement. Anopheles maculipennis var. atroparvus, mue de mâle. Ellevage de Paris, 3 juin r939.

Ces deux tiges sont en connexion (fig. 3), d'une part, avec un épaississement chitineux formé au niveau de la partie interne de l'orifice de la gaine antennaire, et, d'autre part, de chaque côté de la ligne médiane, avec deux talons épais qui se continuent par deux bandes chitineuses allant se perdre sur la face interne de la plaque verticale.

Lorsque l'on examine une nymphe non éclose (fig. 4) avec ces organes en place, après éclaircissement par la potasse, on voit que ces baguettes sont dirigées en bas et en dedans, passant de part et d'autre des pièces buccales. Elles sont cachées par la partie antérieure des globes oculaires au travers desquels on les distingue très nettement. Elles s'arrêtent exactement au niveau du bord inférieur des yeux.

La présence de ces baguettes chitineuses a été signalée par Crawford (1938). Elles peuvent avoir un rapport avec la flexion de la tête, dit

(I) R. Crawford, dans un travail sur les Anophèles de Malaisie (1938), a donné une description très précise de l'anatomie externe des nymphes. C'est la terminologie de cet auteur que nous avons adoptée 
cet auteur, ou avec l'ouverture de la plaque verticale. C'est évidemment ce dernier rôle qui est le plus important.

Ces deux pièces ne sont pas articulées, mais ont des rapports fixes avec la plaque verticale; que ce soit avant ou après l'éclosion, l'angle qu'elles forment avec elle est constant, et le point de jonction est fortement chitinisé. Donc, toute pression exercée d'avant en arrière ou nversement se transmet à la plaque.

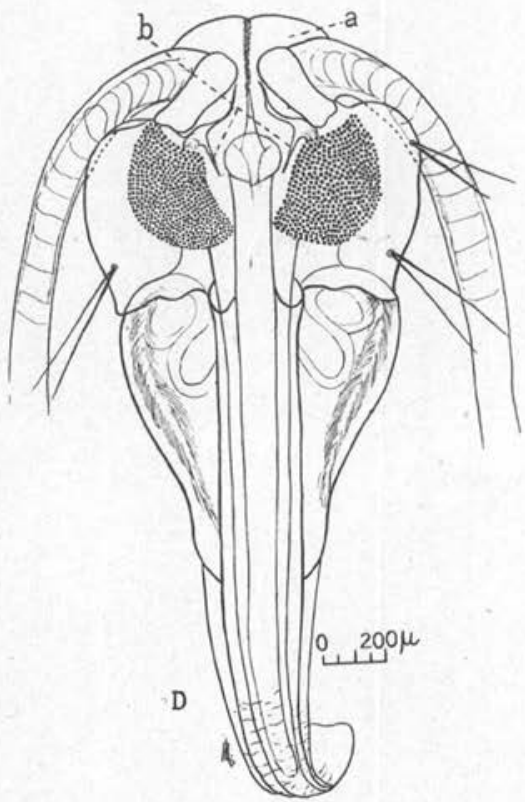

Fig. 4. - Autre nymphe éclaircie par la potasse et vue de face. $a$, plaque verticale; $b$, tiges chitineuses

Au moment de l'éclosion, la tête de l'imago effectue une série de mouvements. Les tractions qui sont exercées d'avant en arrière sur les baguettes se transmettent à la plaque verticale. Cette plaque, tirée d'arrière en avant, est finalement arrachée et rompt ses connexions avec la plaque dorsale en particulier, qui se fend à son tour sur la ligne médiane. L'imago dégage ensuite sa tête et les baguettes, continuant leur mouvement, relèvent progressivement la plaque verticale obturatrice (fig. 5).

Il est certain que les efforts de la tête ne s'exercent pas directement sur ces organes chitineux, mais par l'intermédiaire d'une membrane 
extrêmement ténue, visible par transparence sur les spécimens éclaircis. Cette membrane, doublant la paroi interne de la loge céphalique, entoure étroitement les yeux et la partie postérieure de la tête, et semble s'insérer sur les baguettes. En réalité, il ne s'agit pas d'une

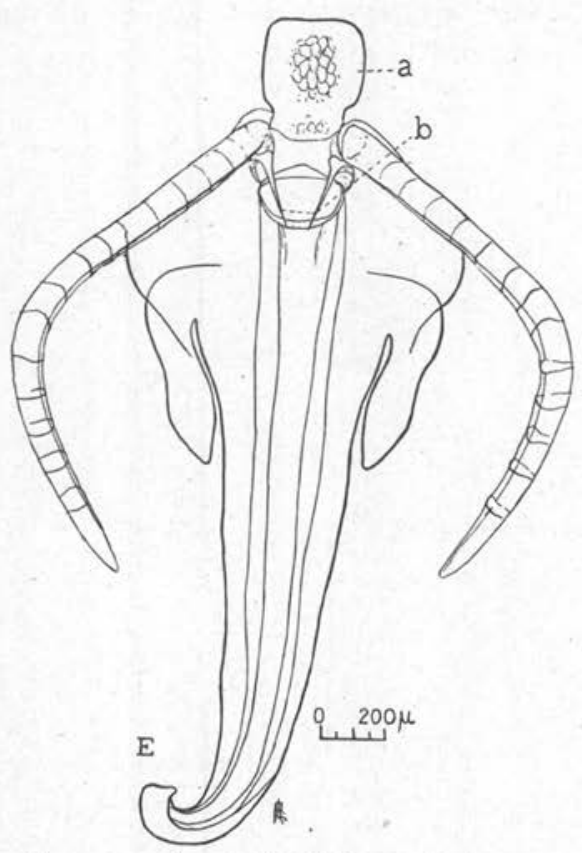

Fig. 5. - Mue d'une nymphe de Culicidé vue de face. $a$, plaque verticale $b$, tiges chitineuses.

véritable insertion, car, après l'éclosion, ces appendices chitineux sont complètement dénudés.

Il existe donc chez la nymphe des Culicidés, comme chez de nombreux insectes, un appareil destiné à faciliter l'éclosion de l'imago.

Laboratoire de Parasitologie de l'Ecole de Médecine de Hanoi. (Direcleur : Professeur H.-G. Galliard). 